\title{
Shanghai Agricultural Products Logistics Distribution Center Location based on Fuzzy AHP
}

\author{
Jin Guo-qin \\ Department of Transport \& Communications \\ Shanghai Maritime University \\ Shanghai, China \\ e-mail: guoqinjin@126.com
}

\author{
Yu Hong-yan \\ Department of Transport \& Communications \\ Shanghai Maritime University \\ Shanghai, China \\ e-mail: yuersuc@163.com
}

\begin{abstract}
Reasonable agricultural products logistics distribution center can not only improve the network system of agricultural products logistics, but can also lower the cost of distribution for agricultural products logistics, improving the living standards of residents. On the basis of assumption that distribution demand points for agricultural products in Shanghai are 117 towns, 13 district governments, 1 People's Government and 1 county government, The cluster analysis method and Floyd algorithm have been employed to achieve minimization of all paths to get the Shanghai agricultural product logistics distribution center alternatives. Combined with the Fuzzy AHP, a comprehensive analysis of Shanghai agricultural products logistics distribution center alternatives is performed. Thus, the result shows Zhenru Town in Putuo district is the most suitable site for establishing the Shanghai agricultural products logistics distribution center, improving the development of the agricultural products logistics, the urban environment and the living standards of residents in Shanghai.
\end{abstract}

Keywords- agricultural products logistics; cluster analysis; Floyd's algorithm; Fuzzy AHP; location.

\section{INTRODUCTION}

Agricultural products logistics distribution center location aims to improve the economic and social benefits of logistics system, combined with the supply and demand conditions of agricultural products, transportation, natural environment and other factors, and takes a systems engineering approach to carry out a decision-making process of geographical locations of distribution center. People reasonably select the location of logistics distribution center that helps to reduce logistics costs, improve service levels, reduce logistics cycle, increase logistics efficiency, especially for agricultural products . Unlike general commodity, agricultural products are required not only to achieve a low freight, but ensure that rot doesn't occur, So the location of agricultural products logistics distribution center has become an important issue.

The three common approaches to conducting this issue are quantitative, qualitative, and mixed methods. At present, mixed methods for the location of agricultural products logistics distribution center are widely used. BI
Ya, LI Wen-feng [1] design the location-allocation system with time and capacity constraints based on covering location problem. Li Zhoufang, Yang Hua, Xu Zhenqiang [2] improved ant colony algorithm with clustering nature for urban vegetable logistics distribution center location. Yan Zhang et al [3] combine Gravity method and Fuzzy AHP for location problem. However, some actual situations, such as traffic conditions, established agricultural distribution centers, urban design and planning and other factors, are not usually considered in the existing research literature on agricultural logistics distribution center.

As discussed above, this paper proposes a novel approach that integrates Cluster analysis , Floyd's algorithm and Fuzzy AHP for selection of Shanghai agricultural products logistics distribution center. First, according to the characteristics of agricultural logistics and traffic conditions in Shanghai, etc., we assume that demand points of agricultural products in Shanghai are 117 towns, 13 district governments, 1People's Government and 1 county government,. And the Cluster analysis is made with the statistical software of SPSS17.0, dividing the data into 36 categories. Furthermore, these categories will be sorted into 17 categories based on improved results; Then applying Floyd's algorithm to MATrix LABoratory (Matlab) for calculating the shortest paths between any two points among 17 categories of agricultural products logistics distribution center in Shanghai. As a result, Shanghai Agricultural Product Logistics Distribution Center Alternatives will be given. Finally, we obtain the optimal distribution center by using Fuzzy AHP based on the entropy weight of every subsystem and indicator in the agricultural products distribution center location in Shanghai.

\section{CLUSTER ANALYSIS OF DEMAND FOR SHANGHAI AGRICULTURAL PRODUCTS LOGISTICS DISTRIBUTION CENTER}

Based on the characteristics of agricultural products logistics, demographic characteristics in Shanghai region 
and ease of data collection, the data of demand points for agricultural products -117 towns, 13 district governments, 1People's Government and 1 county government ,are divided into 36 categories based on the Cluster analysis. Considering the market situation, the result of category will be improved, thereby reducing the complexity of location.

\section{A. K-Means Clustering}

The latitude and longitude coordinates of 132 towns, district (city/county) governments in Shanghai are regarded as the indicator of the Cluster analysis based on SPSS17.0 for K-Means Clustering [4], dividing 132 data into 36 categories, and 36 mean values are taken as various demand coordinates.

Considering that Shanghai Western Suburb International Agricultural Products Trade Center [5] has been eatablished in Qingpu district since 2007, 9 towns and district governments in Qingpu district will be eliminated among 36 categories. And according to the distribution characteristics of each demand - various deviation from each category, we draw a circle with center located in the coordinates of mathematical expectation based on 33 data, and radius which is a straight line from the center to Chongming County area, resulting in improved 17 categories. The results of classification are shown in TABLE I.

TABLE I. CLUSTER ANALYSIS OF 17 CATEGORIES OF DEMAND FOR AGRICULTURAL PRODUCTS

\begin{tabular}{|c|c|c|}
\hline No & Type & Demand points for agricultural products \\
\hline 1 & 2 & Qingcun/Fengcheng/Haiwan Town \\
\hline 2 & 3 & Tinglin/Zhangyan Town \\
\hline 3 & 5 & Hangtou/Xuanqiao/Xinchang Town \\
\hline 4 & 8 & Yangpu/Hongkou District Gov., Gaoqiao/Songnan/Gaojing Town \\
\hline 5 & 9 & \begin{tabular}{|l|} 
Taopu/Nanxiang/Jiangqiao Town \\
\end{tabular} \\
\hline 6 & 10 & Maqiao/Yexie/Chedun Town \\
\hline 7 & 11 & Jiading District Gov., Xuhang/Malu Town \\
\hline 8 & 12 & Songjiang District Gov., Dongjing/Xinqiao/Sheshan/Sijing Town \\
\hline 9 & 14 & \begin{tabular}{|l|l|} 
Luojing/Luodian/Huating Town \\
\end{tabular} \\
\hline 10 & 15 & FFngxian District Gov., Zhuanghang/Zhelin/Nanqiao/Caojing Town \\
\hline 11 & 16 & Chongming County Gov., Gangxi/Jianshe/Chengqiao Town \\
\hline 12 & 18 & Xinzhuang/Qibao/Huacao/Hongqiao/Xujing/Jiuting Town \\
\hline 13 & 20 & Zhuanqiao/Meilong/Wujing/Pujiang/Jinhui Town \\
\hline 14 & 26 & $\begin{array}{l}\text { Putuo/Zhabei/Xuhui/Changning/Huangpu/Jing'an District Gov., Pengpu /Changzheng/Zhenru/ } \\
\text { Dachang/Xinjing Town }\end{array}$ \\
\hline 15 & 29 & Pudong New Area/Municipal Gov.,Sanlin/Zhoupu/Kangqiao/Beicai Town \\
\hline 16 & 30 & Tang/Caolu/Jinqiao/Gaohang/Gaodong/Zhangjiang/HeqingChuansa Town \\
\hline 17 & 35 & Baoshan District Gov., Yanghang/Miaohang/Gucun/yuepu Town \\
\hline
\end{tabular}

\section{Determine Shanghai Agricultural ProduCtS LOGISTICS DISTRIBUTION CENTER ALTERNATIVES BASED ON FLOYD'S ALGORITHM}

Based on the characteristics of 17 categories of Shanghai agricultural products logistics distribution center demand points ,we apply Floyd's algorithm [6] to Matlab, as a platform, to calculate the shortest paths between any two points among 17 categories of agricultural products logistics distribution center in Shanghai. Moreover, taking traffic conditions in Shanghai into account, obtaining Shanghai agricultural products logistics distribution center alternatives. Floyd's algorithm, which belongs to graph theory, is to solve the shortest path between any pair of nodes, mostly applied to select the best single or multiple distribution centers, so that the overall transportation distance is the shortest.

\section{A. Creat rank of a $17 * 17$ distance matrix based on Floyd's algorithm}

According to the Shanghai Highway Network Layout Diagram, we can find the city is criss-crossed with the highway system, and consider there is the only one pathShanghai Yangtze River Tunnel between Shanghai city to Chongming County. Thus, the area in 16th category Chongming County Gov., Gangxi Town, Jianshe Town and ChengqiaoTown, can only be connected with the 30th category (starting point of Shanghai Yangtze River Tunnel), while the remaining 16 categories can be connected between every two categories. Finally, we create rank of a $17 * 17$ distance matrix--- matrix A based on the latitude and longitude coordinates of 17 categories of agricultural products logistics distribution center in Shanghai, determining the agricultural products logistics distribution center alternatives in Shanghai.

The matrix $\mathrm{A}$ is the distance matrix between any two points. And in matrix A, we assume $\infty$ represents that there does not exist any path in any two points. In this paper, there is the only path from Shanghai city to Chongming County -Shanghai Yangtze River Tunnel, and there is no direct path between any other point to Chongming County

\section{B. Apply Floyd's algorithm to MATLAB [7]}

In order to determine the Shanghai agricultural products logistics distribution center alternatives, making the shortest path from the alternatives to all demand points for agricultural products. Thus, we apply Matlab to achieve the Floyd's algorithm, calculating the distance among any two demand points for agricultural products, getting the matrix $\mathrm{B}$, representing the shortest path between any two points.

$$
B=B_{i j}(i=1, \cdots, 17 ; j=1, \cdots, 17)
$$

Summing each column in the matrix $B_{1 j}(j=1, \cdots, 17)$, obtaining the shortest path among all demand points of agricultural products, as shown in Table II below, getting the Shanghai agricultural products logistics distribution center alternatives.

TABLE II. THE TOTAL DISTANCE AMONG ANY DEMAND POINTS FOR AGRICULTURAL PRODUCTS

\begin{tabular}{|c|c|c|c|c|c|c|c|c|c|}
\hline No. & 1 & 2 & 3 & 4 & 5 & 6 & 7 & 8 & 9 \\
\hline Type & 2 & 3 & 5 & 8 & 9 & 10 & 11 & 12 & 14 \\
\hline $\mathbf{B}_{\mathbf{1 j}}$ & 5.7110 & 6.4285 & 4.9518 & 4.1344 & 4.2443 & 4.6125 & 5.8902 & 5.0681 & 5.5500 \\
\hline No. & 10 & 11 & 12 & 13 & 14 & 15 & 16 & 17 & \\
\hline Type & 15 & 16 & 18 & 20 & 26 & 29 & 30 & 35 & \\
\hline $\mathbf{B}_{\mathbf{1 j}}$ & 5.7379 & 11.130 & 4.1762 & 3.9155 & 3.8336 & 4.3354 & 5.4569 & 5.1445 & \\
\hline
\end{tabular}

As can be seen from TABLE II, the optimal result is the $26^{\text {th }}$ category, the shortest distance is 3.8336 , compared with any other 16 categories. So it is recommended to select the five towns (Pengpu, Dachang, Changzheng, Zhenru, Xinjing) in the $26^{\text {th }}$ category as the Shanghai agricultural products logistics distribution center alternatives. Considering that Pengpu Town and Dachang Town have less poor traffic condition than Changzheng town, Zhenru Town and Xinjing Town. Thus, we exclude Pengpu Town and Dachang Town out of the alternatives, and determine Changzheng town, Zhenru Town and Xinjing Town as the Shanghai agricultural product logistics distribution center alternatives. 


\section{Determine Shanghai Agricultural Products} LOGISTICS DISTRIBUTION CENTER BASED ON FUZZY AHP

In order to determine the Shanghai agricultural products logistics distribution center, we use fuzzy AHP to analyze the three alternatives based on Floyd's algorithm.

\section{A. Establishing Hierarchical structure of Shanghai agricultural products logistics distribution center}

Analytic hierarchy process (AHP) was introduced by Professor T. L. Saaty, an American operations researcher, in the 1970. The basic principle of AHP is:

Through the analysis of factors and correlation of complicated system, make the problem methodical and hierarchical in order to objectively build a multi-level analysis structure model[8].

According to the principles and factors affecting agricultural products logistics distribution center location, the evaluation index system is composed of 3 first-grade index,10 second-grade index, and the first level are transport conditions, economic conditions, and environmental benefits. Then we use Yaahp[9], a software, to complete analytic hierarchy process model of Shanghai agricultural products distribution center .

Fig. 1 illustrates the hierarchical structure:

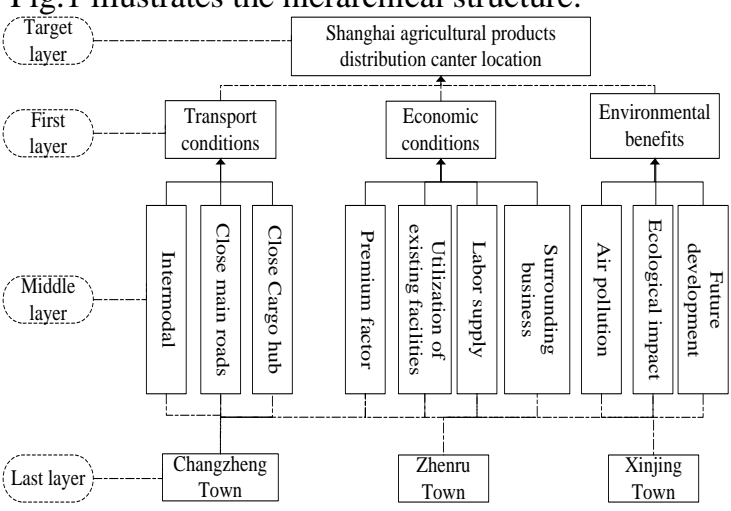

Figure 1. Hierarchical structure of Shanghai agricultural products logistics distribution center location

In the research process of Shanghai agricultural products logistics distribution center location, We collected 10 questionnaires filled by experts from Shanghai Urban-Rural Development and Transport Commission. The valid recovery rate is $83.3 \%$. And then we calculate average rank of indicators to decide the weighting of every indicator. Table III shows the average rank of indicators. We can find transport condition is the most important. The tests of consistency and calculation of weighting can be done both manually and by using the software tool for AHP method---yaahp v7.5.

TABLE III. WEIGHTING OF EVERY FACTOR OF SHANGHAI AGRICULTURAL PRODUCTS LOGISTICS DISTRIBUTION CENTER LOCATION

\begin{tabular}{|c|c|c|}
\hline The goal of decision & First layer (Weighting) & Middle layer (Weighting) \\
\hline \multirow{9}{*}{$\begin{array}{l}\text { Shanghai agricultural } \\
\text { products logistics } \\
\text { distribution center } \\
\text { location }\end{array}$} & \multirow{3}{*}{ Transport conditions $(0.6370)$} & Close main roads $(0.3090)$ \\
\hline & & Close cargo hub $(0.5816)$ \\
\hline & & \begin{tabular}{|l} 
Intermodal (0.1095) \\
\end{tabular} \\
\hline & \multirow{3}{*}{ Economic conditions $(0.2583)$} & \begin{tabular}{|l} 
Utilization of existing facilities $(0.0667)$ \\
\end{tabular} \\
\hline & & \begin{tabular}{|l|} 
Labor supply(0.1491) \\
Premimu factor
\end{tabular} \\
\hline & & \begin{tabular}{|l|} 
Surrounding business $(0.3248)$ \\
\end{tabular} \\
\hline & \multirow{3}{*}{ Environmental benefits $(0.1047)$} & Future development $(0.5816)$ \\
\hline & & \begin{tabular}{|l} 
Ecological impact $(0.1095)$ \\
\end{tabular} \\
\hline & & Air pollution(0.3090) \\
\hline
\end{tabular}

\section{B. Assessment Methodology of Shanghai agricultural} products logistics distribution center alternatives

Fuzzy AHP $[10,11]$ is applied to determine the relative weights of the logistics center location. And Multi-level fuzzy comprehensive evaluation method is a comprehensive analysis of combining method, which combines AHP with fuzzy comprehensive evaluation. Based on the index system of evaluation, the weights of all factors are improved by applying the Fuzzy AHP, and then by using the multilevel fuzzy comprehensive evaluation method, the comprehensive value of Shanghai agricultural products logistics distribution center alternatives is calculated.

The discussed model is given as follow:

Step1: Determine the factors $U$ of evaluation of Shanghai agricultural products logistics distribution center. Each of these factors is represented by a single review. There are 10 reviews, and they constitute a reviews of discourse U.

$$
U=\left\{U_{1}, U_{2}, \cdots, U_{10}\right\}
$$

Step2: Establish the quality level $\mathrm{V}$ of the reviews. In accordance with the degree of pros and cons, devide $\mathrm{U}$ into 4 levels, that is the level of discourse $\mathrm{V}$.

$$
V=\left\{V_{1}, V_{2}, V_{3}, V_{4}\right\}=\{\text { better, good, general, poor }\}
$$

Step3: Establish affiliation and obtain fuzzy evaluation matrix $\mathrm{R}$ of Shanghai agricultural products logistics distribution center, as shown in the Table IV.

TABLE IV. FUZZY EVALUATION MATRIX R OF THREE ALTERNATIVES

\begin{tabular}{|l|c|c|c|c|c|c|c|c|c|c|c|c|}
\hline \multirow{2}{*}{ Index system of evaluation } & \multicolumn{9}{|c|}{ Changzheng Town $\left(\mathbf{R}_{\mathbf{1}}\right)$} & \multicolumn{4}{|c|}{ Zhenru Town $\left(\mathbf{R}_{2}\right)$} & \multicolumn{3}{c|}{ Xinjing Town $\left(\mathbf{R}_{3}\right)$} \\
\cline { 2 - 14 } & Best & Good & Av. & Poor & Best & Good & Av. & Poor & Best & Good & Av. & Poor \\
\hline Close main roads & 0.8 & 0.1 & 0.1 & 0 & 0.8 & 0.2 & 0 & 0 & 0.7 & 0.1 & 0.2 & 0 \\
\hline Close cargo hub & 0.7 & 0.1 & 0.1 & 0.1 & 0.7 & 0.1 & 0.2 & 0 & 0.8 & 0.1 & 0.1 & 0 \\
\hline Intermodal & 0.6 & 0.2 & 0.1 & 0.1 & 0.6 & 0.3 & 0.1 & 0 & 0.6 & 0.1 & 0.2 & 0.1 \\
\hline Utilization of existing facilities & 0.7 & 0.2 & 0.1 & 0 & 0.7 & 0.1 & 0.1 & 0.1 & 0.6 & 0.2 & 0.1 & 0.1 \\
\hline Labor supply & 0.7 & 0.2 & 0.1 & 0 & 0.7 & 0.1 & 0.1 & 0.1 & 0.7 & 0.1 & 0.2 & 0 \\
\hline Premium factor & 0.7 & 0.1 & 0.2 & 0 & 0.7 & 0.1 & 0.2 & 0 & 0.7 & 0.1 & 0.1 & 0.1 \\
\hline Surrounding business & 0.7 & 0.2 & 0.1 & 0 & 0.6 & 0.2 & 0.1 & 0.1 & 0.6 & 0.2 & 0.1 & 0.1 \\
\hline Future development & 0.6 & 0.1 & 0.1 & 0.1 & 0.5 & 0.1 & 0.2 & 0.2 & 0.6 & 0.2 & 0.1 & 0.1 \\
\hline Ecological impact & 0.5 & 0.1 & 0.2 & 0.2 & 0.5 & 0.2 & 0.1 & 0.2 & 0.5 & 0.2 & 0.2 & 0.1 \\
\hline Air pollution & 0.6 & 0.2 & 0.2 & 0 & 0.6 & 0.1 & 0.2 & 0.1 & 0.7 & 0.1 & 0.1 & 0.1 \\
\hline
\end{tabular}

Step4: Make the first Fuzzy comprehensive evaluation.

According to the weights of all evaluation factors, make the fuzzy comprehensive evaluation. Multiply the weights of each middle layer with the corresponding fuzzy judgment matrix to calculate the evaluation vector of every first layer index.

$$
B=A \square R=b_{j}=\max \left\{\left(a_{i} \wedge r_{i j}\right) \mid 1 \leq i \leq n\right\}(j=1, \ldots, n)
$$

TABLE V. THE FIRST FUZZY COMPREHENSIVE EVALUATION OF THREE ALTERNATIVES

\begin{tabular}{|c|l|}
\hline Alternatives & \multicolumn{1}{|c|}{ The first Fuzzy comprehensive evaluation } \\
\hline \multirow{3}{*}{ Changzheng Town } & Transport conditions $(0.6,0.2,0.1095,0.1095)$ \\
\cline { 2 - 2 } & Economic conditions $(0.7,0.2,0.1,0.0667)$ \\
\cline { 2 - 2 } Zhenru Town & Environmental benefits $(0.5,0.1095,0.2,0.2)$ \\
\hline \multirow{4}{*}{ Xinjing Town } & Transport conditions $(0.6,0.3,0.1095,0.1095)$ \\
\cline { 2 - 2 } & Economic conditions $(0.6,0.1,0.1,0.1)$ \\
\cline { 2 - 2 } & Environmental benefits $(0.5,0.2,0.1095,0.2)$ \\
\cline { 2 - 2 } & Eransport conditions $(0.6,0.1095,0.2,0.2)$ \\
\cline { 2 - 2 } & Environmental benefits $(0.5,0.2,0.2,0.1495)$ \\
\hline
\end{tabular}

Step5: Make the second Fuzzy comprehensive evaluation. 
Multiply the weights of each first layer with the first fuzzy judgment matrix to calculate the evaluation vector of every target layer index. as shown in the Table VI.

TABLE VI. THE SECOND FUZZY COMPREHENSIVE EVALUATION OF THREE ALTERNATIVES

\begin{tabular}{|c|c|}
\hline Alternatives & the first Fuzzy comprehensive evaluation \\
\hline Changzheng Town & $(0.5,0.1095,0.2,0.2)$ \\
\hline Zhenru Town & $(0.5,0.2,0.1095,0.2)$ \\
\hline Xinjing Town & $(0.5,0.2,0.2,0.1095)$ \\
\hline
\end{tabular}

Step6: Calculate the total score.

Establish the reviews advantages and disadvantages of assembly hierarchyV=(better,good,general, poor $)=(5,4,3,2)$. The total score of Shanghai agricultural products logistics distribution center location is:

Changzheng Town: $5 \times 0.5+0.1095 \times 4+0.2 \times 3+0.2 \times 2=3.9340$

Zhenru Town: $5 \times 0.5+0.2 \times 4+0.1095 \times 3+0.2 \times 2=4.1685$

Xinjing Town: $5 \times 0.5+0.2 \times 4+0.2 \times 3+0.1095 \times 2=4.1190$

Compared to each other, we can find Zhenru Town(4.1685) is the best optimal result.

\section{Analysis of Shanghai agricultural products logistics distribution center}

Analysis above shows Zhenru town is the most optional site for establishing the Shanghai agricultural products logistics distribution center.

Zhenru Town is located in the northwest of Putuo District, and there are several railroad lines and main roads in it. For example, A11(connect Nanjing and Shanghai) and A12 (connect shanghai and Jiaxing) have relieved the transportation congestion from the northwest of Zhenru Town to Jiangsu Province. A8 (connect shanghai and Hangzhou) has relieved the transportation congestion from the southwest of Zhenru town to Zhejiang Province. All these facilitate the transportation of agricultural products from other provinces to Shanghai, especially from Shanghai Xijiao International Agricultural Trade Center in Qingpu district in Shanghai.

According to the Floyd's algorithm, the total distance from Zhenru town to any other demands for agricultural products is the shortest, thereby reducing the logistics costs of agricultural products. Meanwhile, there are lots of factories, warehouses and enterprises in Zhenru town, and the biggest fruits market in Shanghai is also located in Zhenru town, improving operational efficiency of agricultural products .

In summary, Zhenru town is the most suitable site for establishing the Shanghai agricultural products logistics distribution center.

\section{CONCLUSIONS}

This paper integrates Cluster analysis, Floyd's algorithm and Fuzzy AHP for selection of Shanghai agricultural products logistics distribution center location. First, the cluster analysis is made with the statistical software of SPSS17.0, dividing the distribution data into 36 categories. After dealing with the data, we sorted it into 17 categories; Then applying Floyd's algorithm to Matlab to determine the Shanghai agricultural products logistics distribution center alternatives. Finally, according to the principles and factors affecting agricultural products logistics distribution center location, Zhenru town is the most optimal distribution center by using Fuzzy AHP based on the entropy weight of every subsystem and indicator in the agricultural products distribution center location in Shanghai.

Owing to the characteristics of agricultural logistics and traffic conditions in Shanghai, we assume that distribution points for agricultural products in Shanghai are 117 towns, 13 district governments, 1People's Government and 1 county government, and consider the Shanghai highway network layout, determining Shanghai agricultural products logistics distribution center based on Fuzzy AHP. The proposed methodology provides a more flexible and practical way to select the location of Shanghai agricultural products logistics distribution center for government decision-making.

\section{ACKNOWLEDGMENT}

The research work was supported by the Innovation Program of Shanghai Municipal Education Commission under Grant No. 11YS142, Humanities and Social Science Youth Fund of Ministry of Education under Grant No.13YJC630210 and the Foundation of Shanghai Maritime University under Grant No. 20120080.

\section{REFERENCES}

[1] BI Ya, LI Wen-feng, Research on the Location-Allocation System with Constraints Based on Covering Location Problem, Shanghai Jiaotong Univ.(Sci.), vol.47, pp.495-499, 2013.

[2] Li Zhoufang, Yang Hua \& Xu Zhenqiang, Application of an an colony algorithm with clustering nature in problem of urban vegetable logistics distribution center location, Journal of Chinese Agricultural Mechanization, vol.34, pp.206 209, 2013.

[3] ZHANG Yan, HU Xian-man \& LI Zhen-ping, Distribution Center Location Based on Combining Gravity Method with Fuzzy-AHP Model, Logistics Technology, vol.28, pp.56-58, 2009.

[4] Yuren Zhou, SPSS13.0 statistical software, Southwest Jiaotong University Press: Chendu, pp. 120-132, 2005.

[5] Hua Yan, Yan Sun, The Design of Shanghai Western Suburb International Agricultural Products Trade Center, Shanghai Construction Science, pp.27-30, 2009.

[6] HU Ju-zhou, An Algorithm for Distribution Center Based on the Floyd-Shortest-Path, Journal of Hunan Agricultural University (Natural Sciences), vol.30, pp.382-384, 2004.

[7] Zhang Jing-ru, Yang De-zhi, Floyd short out foot-path algorithm in community hospital application select site, SCIENCE \& TECHNOLOGY INFORMATION, (15), pp.417,486, 2008.

[8] Zheci Tang, Chunlin Guo, Pengxin Hou \& Yubo Fan, Optimal Siting of Electric Vehicle Charging Stations Based on Voronoi Diagram and FAHP Method, Energy and Power Engineering, 2013, 5, pp.1404-1409, doi:10.4236/epe.2013.54B266 Published Online July 2013.

[9] Wang Yali, Song Zhanling, Research on Logistics Distribution Center Location Problem on F-AHP method, CROSS CENTURY, vol.16, pp.90-91, 2008.

[10] Zheci Tang, Chunlin Guo, Pengxin Hou \& Yubo Fan, Optimal Siting of Electric Vehicle Charging Stations Based on Voronoi Diagram and FAHP Method, Energy and Power Engineering, vol.5, pp. 1404-1409, 2013.

[11] Wang Jing-min, Sun Yan-fu, The Application of Multi-Level Fuzzy Comprehensive Evaluation Method in Technical and Economic Evaluation of Distribution Network, Management and Service Science (MASS), 2010 International Conference on Wuhan,pp.1-4,2010. 